\title{
Corn yield response to winter cover crops: An updated meta-analysis
}

\author{
G.S. Marcillo and F.E. Miguez
}

\begin{abstract}
Winter cover crops (WCCs) provide agronomic and environmental benefits, although their impacts on subsequent crop yields have been reported to vary across regions, soils, or under different farm practices. To address the variability in response, previous qualitative and quantitative reviews have summarized the overall yield effects of WCCs. However, the results from such reviews need constant revision as new research is published and interest in the conservation benefits of WCCs increases. Here, we update a previous meta-analysis of WCC effects on corn (Zea mays) yields, which summarized peer-reviewed research from the United Sates and Canada that was published between 1965 and 2004. Our updated data set (1965 to 2015) comprises 268 observations from 65 studies conducted in different regions of the United States and Canada, and includes information about the management practices utilized (i.e., WCC species, nitrogen $[\mathrm{N}]$ fertilization, termination date, tillage, etc.). The effect-size was the response ratio (RR), defined as corn yield following WCCs relative to yield after no cover crop (NC). As in the previous meta-analysis, our results showed a neutral to positive contribution of WCCs to corn yields. On average, grass WCCs neither increased nor decreased corn yields, although corn grown for grain yielded relatively higher than silage corn after grass WCCs. Legume WCCs resulted in subsequent higher corn yields by $30 \%$ to $33 \%$ when $\mathrm{N}$ fertilizer rates were low or the tillage system shifted from conventional tillage (CT) to no-tillage (NT). Mixture WCCs increased corn yields by $30 \%$ when the cover crop was late terminated (zero to six days before subsequent corn). Evidence of 65 years of research showed that uncertainty around the RR has decreased and corn yield response to WCCs has stabilized over time. Our results suggest that benefits of WCCs do not result in reduced corn productivity if properly managed.
\end{abstract}

Key words: corn—cover crops—-meta-analysis—-sustainable production systems

\begin{abstract}
Winter cover crops (WCCs) can improve soil health and provide benefits to subsequent cash crops. WCCs have been shown to effectively prevent soil erosion (Kaspar et al. 2001), reduce nutrient concentration and polluting loads in drainage waters (Kladivko et al. 2014), prevent nutrient leaching (Dabney et al. 2001), and increase soil carbon (C) inputs (Moore et al. 2014). Cumulative benefits of WCCs contribute to enhancing soil and water quality over time, but benefits beyond soil and water conservation, such as increased biological diversity, have been also quantified (Tillman et al. 2004). Winter cover crop adoption has risen (Dunn et al. 2016) in the midst of pressing demands to improve the sustainability of current cropping systems. For instance, initiatives such as the nutrient reduction strategy by the 12 states along the Mississippi River have
\end{abstract}

gen $(\mathrm{N})$ supply, and weed suppression effects. WCC aboveground biomass can reduce soil water losses to evaporation or run-off (Clark et al. 1997; Truman et al. 2003), and WCC root biomass has been shown to improve soil aggregation, pore size distribution, and plant available water (Villamil et al. 2006). In addition, WCCs may contribute additional $\mathrm{N}$ to the subsequent cash crop and reduce fertilizer application requirements. Legume WCCs, for example, fix atmospheric $\mathrm{N}_{2}$ and store organically rich $\mathrm{N}$, which is decomposed by microbial activity and released in plant available form to the next cash crop. Yield increases due to greater biomass and $\mathrm{N}$ production of legume WCCs have been documented (Reeves 1994; Blanco-Canqui et al. 2015), although the magnitude of $\mathrm{N}$ supplied varies among studies because residue decomposition and posterior $\mathrm{N}$ release is highly dependent on climatic conditions and management (Frye et al. 1988). Finally, WCCs may be used to effectively control weeds. When intercropped with corn (Zea mays), the living mulch created by surface cover has provided weed control without the use of herbicides or mechanical tillage (Hartwig and Ammon 2002). Aside from outcompeting growing weeds for light and soil resources, effective rates of weed suppression have been documented also for control of new weeds due to allelochemicals, i.e., chemical compounds that hinder seed germination (Teasdale and Mohler 2000). Despite the positive benefits that WCCs can provide to a cropping system, several disadvantages have also been reported.

WCCs can adversely affect crop yields, although the mechanisms explaining this occurrence are more uncertain. While it is clear that WCCs and main crops compete directly or indirectly for resources, the mechanisms that explain yield penalties are not always consistent. Reduced cash crop populations, soil $\mathrm{N}$ immobilization, and soil water depletion have been proposed to explain yield reductions in subsequent crops. WCCs might lead to a reduction of cash crop populations because of interference between cover crop residue and farm equipment, which cre-

Guillermo S. Marcillo is a graduate research assistant in the Department of Agronomy at lowa State University in Ames, lowa. Fernando E. Miguez is an associate professor in the Department of Agronomy at lowa State University in Ames, lowa. 
ates an incomplete seed furrow and impedes adequate seed to soil contact (Eckert 2013; Kaspar and Bakker 2015). Also, lower crop populations have been associated with slow emergence due to lower soil temperatures and seedling inhibition by allelochemicals released by WCC residues (Balkcom et al. 2007). Another detrimental effect of WCCs is reduced inorganic $\mathrm{N}$ availability because of direct uptake during WCC active growth or $\mathrm{N}$ immobilization during residue decomposition (Wagger and Mengel 1993; Kaspar and Bakker 2015). Low quality residue and insufficient biomass accumulation might lead to incomplete release of $\mathrm{N}$ to the next crop, decreasing yields unless $\mathrm{N}$ is supplemented (Blanco-Canqui et al. 2015; Dabney et al. 2001; Reeves 1994). Finally, WCCs may reduce soil water storage, depleting reserves and negatively affecting yields of subsequent crops. Years with below normal precipitation (Munawar et al. 1990), coarse drought-prone soils, or soils insufficiently recharged prior to main crop early growth, may worsen water depletion linked to reduced crop yields (Reeves 1994).

As cover crops may result in positive or negative effects on yield, discrepancies arise in regard to their overall contribution to a cropping system. Several systematic reviews have been conducted to analyze the overall effect of WCCs, factoring in environment and management conditions driving the variability in response. For example, Unger and Vigil (1998) analyzed cover crop effects in relation to water use across regions, concluding that WCC effects are mostly positive in humid and subhumid areas and provide additional nutrient cycling benefits compared to other water conserving practices alone, such as conservation tillage. Blanco-Canqui et al. (2015) found overall positive yield influences in a summary of WCC research from temperate soils, and Fageria et al. (2005) concluded in their review that proper WCC management contributes to improving main crop yields and soil water quality. Likewise, by reviewing promising WCC species across different regions, Snapp et al. (2005) pointed out overall benefits as long as farmers set specific goals for their operations. Most reviews have systematically compiled the literature around WCCs in relation to crop yields, yet only a few have included a statistical treatment or meta-analysis of the data sets derived from the literature review (Valkama et al. 2015; Sileshi et al. 2008; Tonitto et al. 2006; Miguez and Bollero 2005).
Meta-analysis methods have been applied to analyze agronomic performance, allowing for the combination of independent research to address specific hypotheses. The techniques of meta-analysis ensure a proper selection of studies, synthesis of results, and control of bias resulting from missing representative studies on a topic (Pai et al. 2004) Meta-analysis also offers statistical advantages in agricultural research. By pooling observations from several studies, meta-analysis extends the low statistical power associated with single studies (e.g., decreasing the likelihood of noting an absence of differences when there are in fact significant effects [Arnqvist and Wooster 1995]). Further, meta-analysis allows researchers to discriminate the variation due to experimental or management conditions between studies, and model it explicitly (Kiær et al. 2009). Updating meta-analysis studies is routinely done in the medical and social sciences, but it has rarely been conducted in agriculture. Failing to update a meta-analysis can result in holding results as fixed without considering recent methodological advances, or simply, the accumulation of new evidence on a major research topic since its publication.

The meta-analysis by Miguez and Bollero (2005) provided insight about the influence of WCCs on corn production. By reviewing 40 years of WCC research in the United States and Canada, WCCs were shown to provide neutral to $21 \%$ increase in corn yields across different regions and management conditions. Despite these results, there are agronomic and methodological reasons that motivate an update of this review. WCCs are arguably even more relevant today as current and new users call for better management practices to maximize conservation benefits while reducing economic risk from their farm investments. Interest in cover crops has expanded along with the need for management and technical information about their use since the release of the nutrient reduction strategies (INRS 2016) within the Midwest (ILF 2015). Also, WCC research since the first meta-analysis has continued, and studies that investigate a variety of topics, such as species selection, crop yield effects, nutrient leaching, and erosion control are continually being published.

As more research is accumulated on a topic, specialists recommend including new references and updating a meta-analysis so conclusions from the previous work may be revised (Moher et al. 2008; O'Connor et al. 2008). Among the few examples in agriculture, expanding the number of publications, and in some cases revisiting the structure of the supporting data sets, has resulted in a major shift of the conclusions from previous meta-analyses, such as the case of organic versus conventional yields (Badgley et al. 2007; Seufert et al. 2012; Ponisio et al. 2015). In addition, updating a meta-analysis does not only involve including additional observations from the most recent literature, but can also consider changes or improvement in methods for increased robustness of the results (O'Connor et al. 2008). For instance, in reviewing worldwide crop yield responses to climate change, Challinor et al. (2014) updated a previous meta-analysis (IPCC 2007) and introduced more robust methods to capture yield responses to warming conditions not detected before. Therefore, a fresher outlook to analyze WCC contribution to corn yields is needed, along with an assessment of the conditions by which WCC contribution differs across different regions, in light of the evidence of the last 10 years of research.

For this updated meta-analysis, we maintain the same methods and research questions from Miguez and Bollero (2005). Including information about the cropping system, we update the overall corn yield response to WCCs based on peer-reviewed publications from the last 10 years (2005 to 2015). Specifically, our objectives were to (1) estimate mean corn yields comparing systems with and without WCCs, (2) assess variability in corn yield response to WCCs affected by management conditions (e.g., N fertilization, WCC species, WCC planting and termination dates, tillage, etc.), and (3) assess temporal changes in corn yield response to WCCs depending on evidence accumulated over time.

\section{Materials and Methods}

Database Preparation. Following the criteria outlined by Miguez and Bollero (2005), we updated a previous database of 37 peer-reviewed publications, which included studies from 1965 to 2004. We used Institute for Scientific Information (ISI) Web of Science (Thomson Reuters, New York, New York) and Google scholar (Google Inc., Mountain View, California) to search for studies in the 2004 to 2015 period that matched the following Boolean expressions: "Corn yield and winter cover crops or cover crops.” Furthermore, 
studies included in the database had to meet all the following criteria:

1. Yield records came from corn following a cover crop treatment, and corn following no cover (NC).

2. Yields were reported in more than one year or location.

3. Enough information was provided to compute study variances.

4. The studies were conducted in the United States or Canada.

In addition to the original 37 publications, 28 articles out of 395 were recovered in this fashion (table 8). Thus, the updated database comprises 65 articles with publication range between 1965 and 2015. From the total, 58 studies were conducted in the United States and 7 in Canada.

Following standard meta-analysis methods, we included factors in the database with potential to moderate WCC effects on corn yields. Factors refer to conditions of the cropping system employed in a study, such as tillage, WCC species, region, corn yield, $\mathrm{N}$ fertilizer rate (NFR), and WCC termination date. An additional variable, which indicates the type of corn yield (as a categorical variable), was included to describe whether yields of the following crop were reported for grain or biomass for silage. For ease of comparison, we set the levels of each factor at those defined previously by Miguez and Bollero (2005). Additionally, we analyzed the following factors not included in the previous meta-analysis: WCC seeding period, soil texture, WCC growing season, and WCC biomass. Seeding period included two levels: (1) late seeding for WCCs drilled or broadcasted after corn harvest, and (2) early seeding for WCCs interseeded at late stages of standing corn. To reduce soil textural classification to a manageable number, we defined the following five categories of soil texture (Wösten et al. 1999): very fine, fine, medium, medium fine, and coarse. WCC growing season refers to Julian days elapsed between the average seeding and average termination dates reported in a study. Biomass accounts for aboveground WCC dry matter recorded at, or near, termination of the cover crop. Table 1 displays a full description of the moderators of yield response to WCCs, distinguishing between continuous and categorical, and including number of observations for the two-time periods in the meta-analysis.

\section{Table 1}

Moderators of corn yield response to winter cover crops (WCC) included in the updated meta-analysis, 1965 to 2015.

\begin{tabular}{|c|c|}
\hline Variable & $\begin{array}{l}\text { Description for factors and } \\
\text { mean and range for continuous variables }\end{array}$ \\
\hline Tillage $(n=268)$ & Conventional, no-till \\
\hline WCC species $(n=268)$ & Grass, legume, and mixture \\
\hline Region $(n=268)$ & $\begin{array}{l}\text { Southeast, Northeast, Canada, } \\
\text { North Central, Great Plains, Southwest, } \\
\text { and Northwest }\end{array}$ \\
\hline Corn yield $(n=268)$ & Grain and biomass \\
\hline Nitrogen fertilizer rate (NFR) $\left(\mathrm{kg} \mathrm{ha}^{-1}\right)(n=268)$ & Low: 0 to 99; mid: 100 to 199; high: >200 \\
\hline WCC termination (days before corn) $(n=215)$ & 15 (0 to 35$)$ \\
\hline WCC seeding period $(n=248)$ & $\begin{array}{l}\text { Early: before corn harvest; } \\
\text { Late: after corn harvest }\end{array}$ \\
\hline Soil texture $(n=238)$ & $\begin{array}{l}\text { Very fine, fine, medium, medium fine, } \\
\text { and coarse }\end{array}$ \\
\hline WCC growth season (Julian days) $(n=207)$ & 250 (60 to 300$)$ \\
\hline WCC biomass $\left(\mathrm{Mg} \mathrm{ha}^{-1}\right)(n=194)$ & 1.2 (0.6 to 3$)$ \\
\hline
\end{tabular}

Data Analysis. The dependent variable indicates the efficacy of a cover crop treatment relative to $\mathrm{NC}$ control (i.e., effect size for a study), and was quantified as a response ratio (RR). RRs have been used to evaluate cover crop performance under different scenarios (Miguez and Bollero 2005; Kuo and Jellum 2000; Olson et al. 1986). RR for a study is calculated by dividing corn yield following a WCC treatment to corn yield following NC:

$R R=\frac{\text { Yield }_{w c c}}{\text { Yield }_{n c}}$.

Depending on the experimental layout, a cover crop treatment in combination with another factor produced multiple RRs for a study. For instance, WCC species and N combined in a factorial arrangement resulted in an RR for each species calculated at each application rate. Finally, RRs were log-transformed to normalize the data and ensure that changes in numerators and denominators were affected equally (Borenstein et al. 2010; Basche et al. 2014).

Variability due to differences within and between studies was assessed following the methods by Borenstein et al. (2010). Standard deviations (SD), yields (Y), and sample sizes (n) for WCC and NC treatments were used to estimate within-study variances:

$v_{i}=\frac{S D_{w c c}^{2}}{n_{w c c} \times Y_{w c c}^{2}}+\frac{S D_{n c}^{2}}{n_{n c} \times Y_{n c}^{2}}$.
Within-study variances of 55 studies were determined following such an approach. One study (Singer et al.2008) reported neither SD nor $n$, yet the authors provided their original data sets upon request. The two remaining studies (Bundy and Andraski 2005; Crandall et al. 2005) provided either one or all of the following statistics: least significant differences (LSD), standard error of the mean (SE), coefficient of variation (CV), or 95\% confidence intervals (CI), from which standard deviations and within-study variances were recovered. On the other hand, between-studies variance $\left(\sigma_{b}^{2}\right)$ quantifies true differences in corn yield response across WCC studies (i.e., nonsampling error related), and was estimated following a weighting approach to correct for unequal within-study variances (Borenstein et al. 2010).

Homogeneity in the distribution of $\log$-RR (i.e., null hypothesis that WCC had similar effects on corn yield across studies) was tested by computing total variance, or weighted total sum of squares for log-RR (Q-statistic). Weights in the calculation of Q equaled to the inverse of within-study variances (Viechtbauer 2010). The Q-statistic follows a chi-square distribution with $(n-1)$ degrees of freedom; therefore, a $\mathrm{Q}$ estimate whose $p$-value is less than 0.05 led to reject the null hypothesis and conclude that studies did not share a common effect size (i.e., WCC effects differed across studies). Further, we used the I-square $\left(\mathrm{I}^{2}\right)$ index to determine the presence of heterogeneity in our data set. Such 
an index reflects the proportion of observed variability indicated by between-study variance, or the heterogeneity in WCC effects arising from reasons other than sampling error or year/location effects. The I-square index is computed by dividing the difference between total variance $(\mathrm{Q})$ and its degrees of freedom $(n-1)$ by total variance itself (Huedo-Medina et al. 2006). $\mathrm{I}^{2}$ values above $25 \%$ or $50 \%$ suggest a significant amount of heterogeneity, for which additional techniques, such as subgroup homogeneity analysis or meta-regression, can be used to explore additional reasons for such heterogeneity in response. (Higgins and Thompson 2002).

Evidence of heterogeneity in $\log -\mathrm{R} R$ allowed for the inclusion of moderators that explained the significant variance between studies. As such, we partitioned total variance (Q) into between-group components for each factor moderating WCC response in table 1 and tested whether they were significant if $p<\alpha(0.05)$. For the significant moderators, a subgroup analysis of homogeneity was conducted, further partitioning variance into within-group components (i.e., levels within such significant factors), and using $\alpha=0.01$ to protect against Type I errors (i.e., falsely reject a true null hypothesis). Finally, weighted mean log-RR and 95\% CI were estimated using weights equal to the reciprocal of total variance (i.e., within-study variance computed with equation 2 plus between-studies variance estimated in the homogeneity analysis):

$$
\overline{\log (\mathrm{RR})}=\frac{\sum_{i=1}^{n} \frac{1}{\left(v_{i}+\sigma_{b}^{2}\right)} \log \left(R R_{i}\right)}{\sum_{i=1}^{n} \frac{1}{\left(v_{i}+\sigma_{b}^{2}\right)}}
$$

For ease of interpretation, weighted mean $\log$-RRs were back transformed to ratio form by applying anti-logs.

Sensitivity Analysis and Publication Bias. We conducted a sensitivity analysis to detect temporal changes in corn yield response to WCCs given the evidence of 50 years of research in the United States and Canada. A cumulative random effects meta-analysis (CMA) without moderators, following Viechtbauer (2015) and Leimu and Koricheva (2004), was conducted to estimate weighted mean effect size while controlling for publication year of the studies in the database. In the CMA, after the earliest available study was entered, observations were sorted in chronological order, pooled by publi- cation year, and added one year at a time. Observations pertaining to studies published in the same year were randomly allocated. Then, yearly weighted mean log-RR and 95\% CIs were recalculated following the same estimation procedures for mean effect size in the homogeneity analysis (equation 3). In other words, the CMA tested significant differences of WCC effects and estimated mean yield response at every available publication year between 1965 and 2015 (i.e., indication of time trends of WCC driven variability in corn yields or how evidence in WCC effects have evolved over time).

To investigate publication bias in the data set, we used funnel plots of effect size (log-RR) against the inverse of standard error. Because such plots indicate how effect size and study precision are related, a symmetric funnel shape in the scattering of individual observations is expected, with increasing scatter for less precise studies. Asymmetric funnels usually depict a relationship between effect size and precision, which may suggest indication of small studies failing to report nonsignificant results, suppression of data relevant to the meta-analysis, etc. (i.e., publication bias) (Anzures-Cabrera and Higgins 2010).

Meta-Regression. To account for additional reasons that explain between-study variability, we explored the quantitative relationship between corn yields and WCCs by including management factors of the cropping system. Meta-regression models have been applied to capture differences between studies that explained variability of grain yield responses to trial variety mixtures (Kiaer et al. 2009), grain yield responses to catch crops affected by fertilization rates (Valkama et al. 2015), or crop yield responses to tillage affected by crop rotation and degree of tillage intensity (Van den Putte et al.2010). In the meta-regression model, the dependent variable was log-RR, and was regressed against the continuous variables $\mathrm{N}$ fertilization and WCC termination. Mixed models with interactions were fitted, incorporating effects at the study level (St-Pierre 2001), and including the fixed effect factor WCC species along with random terms for the slopes and intercepts of each study in the database. Weighted models, robust to compensate for the unequal variance effect (Khoshravesh et al. 2015), were fitted for $\mathrm{N}$ fertilization and WCC termination. The models were run separately because of unequal number of observations and to avoid overparameterization in a full model.

The meta-analysis (homogeneity analysis, subgroup analysis, mean effect size estimation, funnel plotting, and sensitivity analysis) was conducted through functions available in the metafor R-package, version 1.9-8 (Vietchbauer 2015). To fit the mixed effects model and estimate parameters for the meta-regression, we used the R-package linear mixed-effects (lme4), version 1.2 (Bates et al. 2015).

\section{Results and Discussion}

Overall. We found evidence of heterogeneity in our cover crop database (table 2). The previous meta-analysis (Miguez and Bollero 2005) reviewed cover crop effects reported by 37 publications, finding a large between-studies variability (i.e., $\mathrm{I}^{2}=59 \%$ ) in 160 observations. In this updated meta-analysis, the sample size increased by $67.5 \%$, including observations from 28 additional publications, resulting in a higher and significant sum of squares ( $\mathrm{Q}=706, n=268$, and $p<0.001$; table 2 ). Between-studies variance for the previous and the updated meta-analyses was estimated at 0.007 and 0.008 , respectively, which confirmed the presence of more systematic causes for the variation in yield response to WCCs (i.e., $I^{2}=62 \%$ ). In exploring the factors that moderated yield response to WCCs (table 3 ), we found significant effects of WCC species, region, and NFR, as previously reported by Miguez and Bollero (2005). Additionally, we found significance for WCC termination (i.e., days before subsequent corn) in the updated meta-analysis. Because WCC species accounted for much of the variability, we repeated the homogeneity analysis at the following three levels of this category: grass, legume, and mixture WCCs.

Winter Cover Crop Species. We found significant differences in yield response for the three WCC groups (table 4), and not only for the legume subgroup as in Miguez and Bollero (2005). Variability partition, evaluated through homogeneity analysis at each level of WCC species (table 5), revealed different moderators of yield response for grass, legume, and mixture WCCs.

Mixtures. The weighted mean response for the mixture group was 1.13 , with a $95 \%$ CI not including 1 , which means that corn following a mixture WCC treatment showed 13\% higher average yields than NC (figure 1 ). While this estimation is lower relative to the previous meta-analysis (21.5\%; Miguez 
and Bollero 2005), the CI has also narrowed due to the larger sample size for the update (i.e., $n=10$ and $n=28$ for the first and the updated meta-analysis, respectively). Previous research has attributed corn yield benefits of mixture WCCs to greater biomass production, which reduces soil erosion and improves weed control (Kuo and Jellum 2002). Further, biomass production of cover crop mixtures has been reported as highly dependent on termination date (Clark et al. 1997) as it affects composition and quality of the cover crop residue (Ruffo and Bollero 2003). By including additional observations for mixture WCCs, we were able to detect significant differences for biomass and termination date not reported before (Miguez and Bollero 2005). Mixture WCC observations were not homogeneous $(\mathrm{Q}=92.00, n=28$, $p<0.001$; table 4). Between-studies variance was estimated at 0.015 and explained $70 \%$ of total variability (i.e., $\mathrm{I}^{2}=70$ ). The homogeneity analysis for mixture WCCs showed significant effects for WCC termination and WCC biomass, suggesting that the two factors explained a considerable amount of variation in yield response $(p<0.001$; table 5$)$.

The homogeneity analysis for WCC termination within mixture showed that the $\mathrm{RR}$ increased as termination date decreased (figure 2). When a mixture WCC was terminated 14 or more days ahead of the subsequent corn crop, yields were lower but not significantly different than NC. Midtermination did not exhibit differences either for corn following mixture WCCs or NC, yet the mean RR was above 1 . On the contrary, mixture WCCs that were late terminated (i.e., zero to six days before subsequent corn) displayed a significant 30\% increase in corn yield relative to NC. Late and mechanically terminated mixtures, as in Wortman et al. (2013), have been shown to result in higher corn grain yields in relation to NC $(16 \%$ to $22 \%)$ because of increased biomass that reduced early-season weeds. Managing mixtures poses more challenges compared to a single species system, yet the higher seeding rates associated with them can lead to greater biomass production (Kuo and Jellum 2002). In turn, timely WCC termination accompanied by residue management practices maximize the benefits that double or multiple WCC systems can bring to subsequent cash crops, such as increased $\mathrm{N}$ availability through biological $\mathrm{N}_{2}$ fixation and nutrient cycling (Kuo and Sainju 1998),

\section{Table 2}

Homogeneity analysis of corn yield response to winter cover crops (WCC). Total sum of squares $(Q)$, between-study variance $\left(\sigma_{b}^{2}\right)$, heterogeneity $\left(I^{2}\right)$, and number of observations for two periods of analysis.

\begin{tabular}{llllll}
\hline Period & $\mathbf{Q}$ & $\mathbf{\sigma}_{b}^{2}$ & $\mathbf{I}^{\mathbf{2}}$ & Studies & Observations $(\boldsymbol{n})$ \\
\hline 1965 to 2004 & $386(0.001)$ & 0.007 & 58.81 & 37 & 160 \\
2005 to 2015 & $300(0.001)$ & 0.008 & 64.32 & 28 & 108 \\
1965 to 2015 & $706(0.001)$ & 0.008 & 62.18 & 65 & 268 \\
\hline
\end{tabular}

Notes: Values between parentheses denote significance at $p<0.05$.

$\mathrm{I}^{2}=\frac{\mathrm{Q}-(n-1)}{\mathrm{Q}} \times 100$

\section{Table 3}

Homogeneity analysis for moderators of yield response to winter cover crops (WCC). Between-groups sum of squares $(Q), p$-values $(p)$, and number of observations $(n)$ for the updated meta-analysis (1965 to 2015).

\begin{tabular}{lccl}
\hline Moderator & \multicolumn{1}{l}{$\mathbf{Q}$} & $\boldsymbol{p}$ & $\boldsymbol{n}$ \\
\hline Tillage & 0.00 & 0.970 & 268 \\
WCC species & 70.03 & $<0.0001$ & 268 \\
Region & 37.80 & $<0.0001$ & 268 \\
Corn yield & 0.68 & 0.411 & 268 \\
Nitrogen fertilizer rate (NFR) & 35.98 & $<0.0001$ & 268 \\
WCC termination & 8.50 & 0.010 & 215 \\
WCC seeding period & 2.74 & 0.431 & 248 \\
Soil texture & 1.06 & 0.786 & 238 \\
WCC growth season & 0.04 & 0.827 & 207 \\
WCC biomass & 3.40 & 0.070 & 194 \\
\hline
\end{tabular}

Note: $p<0.05$ indicates significant effects for a moderator of yield response to WCC.

\section{Table 4}

Homogeneity analysis of corn yield response to winter cover crops (WCC). Sum of squares (Q), between-study variance $\left(\sigma_{b}^{2}\right)$, heterogeneity $\left(I^{2}\right)$, and number of observations $(n)$ for the three levels within WCC species.

\begin{tabular}{llllll}
\hline Species & $\mathbf{Q}$ & $\mathbf{\sigma}_{b}^{2}$ & $\mathbf{I}^{\mathbf{2}}$ & Studies & Observations $(\boldsymbol{n})$ \\
\hline Grass & $203(0.001)$ & 0.002 & 31.87 & 47 & 140 \\
Legume & $352(0.001)$ & 0.016 & 71.63 & 36 & 101 \\
Mixture & $92(0.001)$ & 0.015 & 70.65 & 13 & 28 \\
\hline
\end{tabular}

Note: Values between parentheses denote significance at $p<0.05$

$$
\mathrm{I}^{2}=\frac{\mathrm{Q}-(n-1)}{\mathrm{Q}} \times 100
$$

increased $\mathrm{N}$ mineralization and crop uptake (Sainju and Singh 2001), and soil moisture conservation before main crop planting (Wortman et al. 2012).

Grasses. Grass WCCs showed neutral effects on corn yields. The weighted mean response was 1 (0.98 to 1.02), which means that corn yields following a grass WCC were not significantly different than NC (figure 1). The weighted mean RR for grass WCCs remained relatively unchanged relative to the previous meta-analysis $(0.99, n=70)$, although the sample size has doubled, including 70 additional observations. Most new observations came from small grain studies published during the 2005 to 2015 period in US northern regions and Canada. While corn yields neither increased nor decreased, grass WCC effects were not homogeneous, and hence, differed across studies $(\mathrm{Q}=203.8$, $n=140, p<0.0001$; table 4). Betweenstudies variance was estimated at 0.002 and 


\section{Table 5}

Subgroup homogeneity analysis. Sums of squares $(Q), p$-values $(p)$, and number of observations $(n)$ for the moderators of corn yield response within the three levels of winter cover crop (WCC) species.

\begin{tabular}{|c|c|c|c|c|c|c|c|c|c|c|}
\hline Species & Coefficient & Tillage & Region & $\begin{array}{l}\text { Corn } \\
\text { yield }\end{array}$ & NFR & $\begin{array}{l}\text { wCC } \\
\text { termination }\end{array}$ & $\begin{array}{l}\text { WCC } \\
\text { seeding } \\
\text { period }\end{array}$ & $\begin{array}{l}\text { Soil } \\
\text { texture }\end{array}$ & $\begin{array}{l}\text { WCC } \\
\text { growth } \\
\text { season }\end{array}$ & $\begin{array}{l}\text { WCC } \\
\text { biomass }\end{array}$ \\
\hline \multirow[t]{3}{*}{ Mixture } & $\mathrm{Q}$ & 3.004 & 4.275 & 0.0588 & 0.3836 & 39.65 & 1.112 & 3.340 & 1.204 & 9.671 \\
\hline & $p$ & 0.083 & 0.370 & 0.808 & 0.825 & $<0.0001$ & 0.573 & 0.060 & 0.273 & $<0.001$ \\
\hline & $n$ & 28 & 28 & 28 & 28 & 25 & 28 & 28 & 26 & 26 \\
\hline \multirow[t]{2}{*}{ Grass } & $\mathrm{Q}$ & 4.491 & 7.374 & 6.157 & 0.504 & 0.033 & 2.263 & 3.213 & 2.414 & 3.156 \\
\hline & $n$ & 139 & 139 & 140 & 139 & 109 & 126 & 125 & 109 & 102 \\
\hline \multirow[t]{3}{*}{ Legume } & $\mathrm{Q}$ & 6.578 & 15.460 & 0.323 & 20.170 & 1.768 & 2.672 & 2.220 & 3.470 & 1.363 \\
\hline & $p$ & 0.0103 & 0.008 & 0.569 & $<0.0001$ & 0.413 & 0.445 & 0.695 & 0.062 & 0.243 \\
\hline & $n$ & 100 & 101 & 101 & 100 & 81 & 93 & 84 & 72 & 70 \\
\hline
\end{tabular}

Notes: 0.01 was used for protection against Type I errors. NFR = nitrogen fertilizer rate.

accounted for $32 \%$ of total variability in grass observations (i.e., $\mathrm{I}^{2}=32$ ). The homogeneity analysis for grass WCCs determined significant variation in response due to the corn yield variable $(p<0.01)$, suggesting different RRs to be estimated for grain and silage corn, respectively (table 5).

From the homogeneity analysis for grass WCCs, it was determined that the RR increased when corn was harvested for grain, and decreased for silage corn (figure 3). When corn harvested for silage followed a grass WCC, yields were lower but not significantly different from NC. Corn harvested for grain yielded relatively higher than silage corn after grass WCCs, yet did not show significant differences with respect to NC. Although corn yields for the grass group were not significantly different from NC, differences in response for silage and grain systems may occur as the result of extended growing periods in silage production, or diminishing quantity and quality of ears produced in grain systems. Silage production, for example, allows for extended harvest periods when planting is delayed, but the risk of erosion and nitrate $\left(\mathrm{NO}_{3}^{-}\right)$leaching increases due to the aggressive removal of residue, which may impact yields ultimately. In dairy cropping systems where grass WCCs help mitigate environmental impacts from silage production, Krueger et al. (2011) reported biomass yield penalties when rye (Secale cereal L.) WCC grew four extra weeks relative to early terminated rye; otherwise neutral in terms of its impacts to subsequent silage yields. Also, the likelihood of silage yield penalties after grass WCCs might be reduced by selecting less winter-hardy species. For instance, Hashemi et al. (2013) reported

\section{Figure 1}

Mean response ratio (RR; yield of corn following winter cover crops/yield of corn following no cover [ycc/ync]) and $95 \%$ confidence interval (horizontal bars) for three levels of winter cover crops.

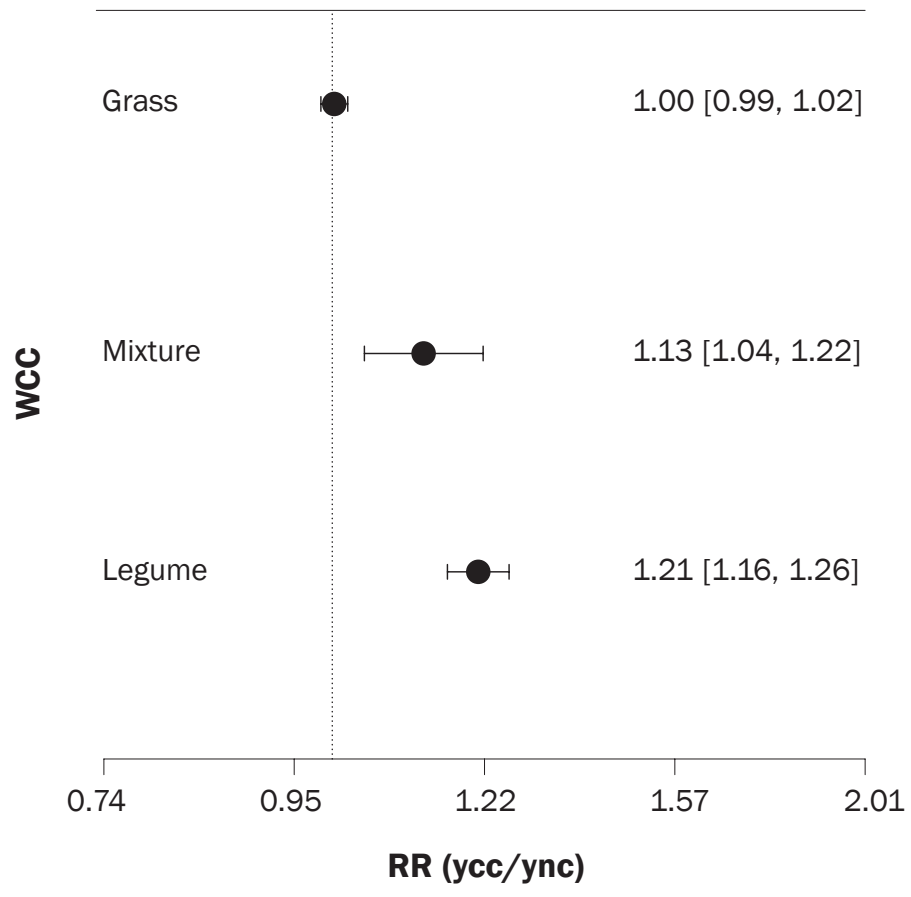

$41 \%$ higher silage for corn that followed oats (Avena sativa) relative to NC, possibly due to winter-kill and increased time for decomposition and greater $\mathrm{N}$ release. In contrast, neutral grain yield effects have usually been associated with grass WCCs, although yield penalties may still occur. To explain yield reductions, several hypotheses have been proposed, such as reduced corn populations and higher number of barren plants resulting from poor seed to soil contact due to interference of WCC residue and planters (Kaspar and Bakker 2015), reduced soil temperatures that slow emergence (Kaspar et al. 1990), or allelopathic effects inhibiting germination (Reberg-Horton et al. 2005).

Legumes. Legume WCCs showed overall positive effects on corn yields. The weighted mean response was 1.21 (1.17 to 1.29$)$, which means that corn that followed a legume 


\section{Figure 2}

Mean response ratio (RR; yield of corn following winter cover crops/yield of corn following no cover [ycc/ync]) and $95 \%$ confidence interval (horizontal bars) for the three levels of termination date (days before corn) within mixture.

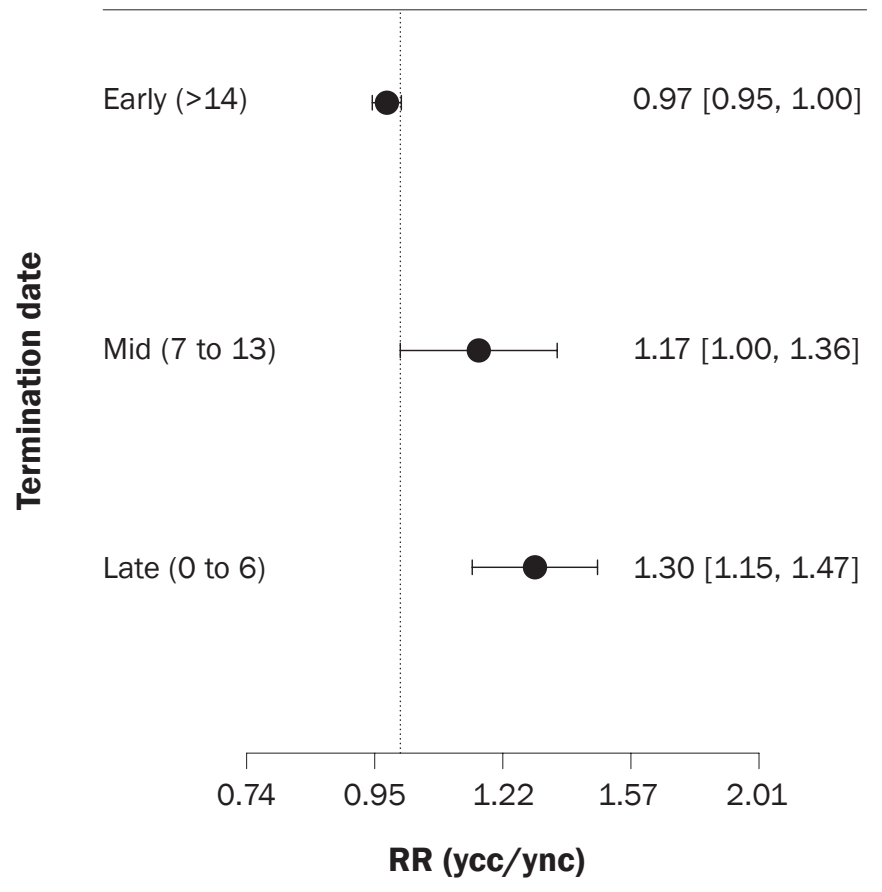

\section{Figure 3}

Mean response ratio (RR; yield of corn following winter cover crops/yield of corn following no cover [ycc/ync]) and $95 \%$ confidence interval (horizontal bars) for the two levels of the corn yield variable within grass.

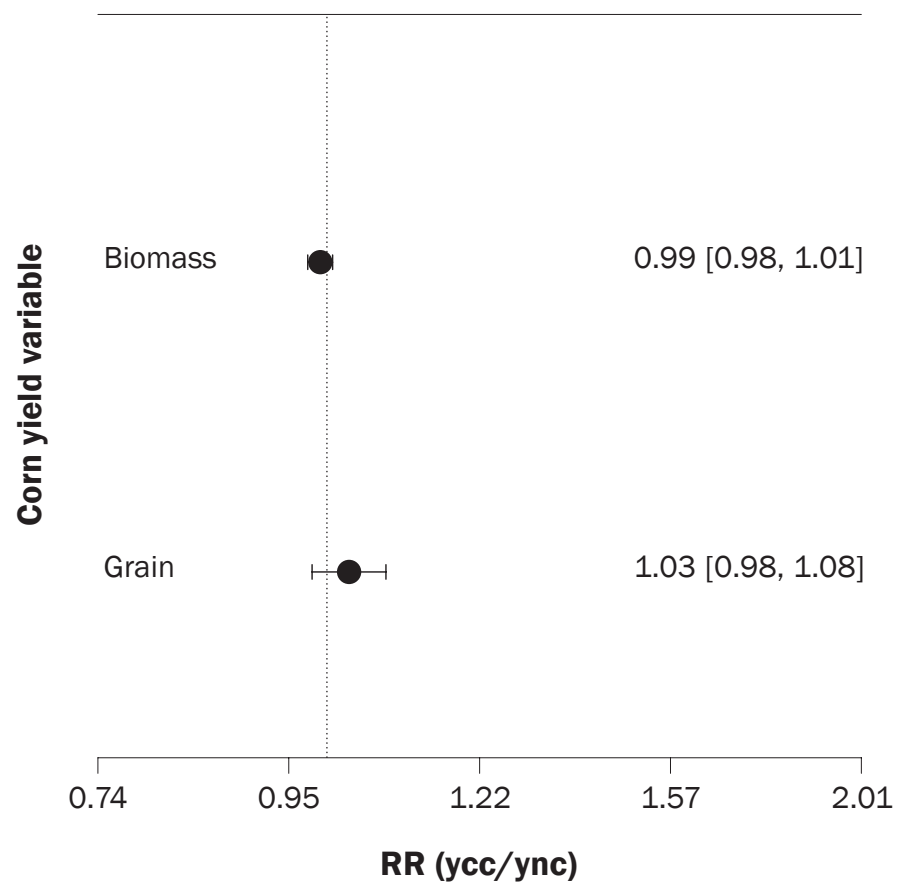

WCC yielded 21\% more than without a cover (figure 1). The weighted mean RR for legume WCCs has also remained stable when compared to the previous meta-analysis (1.21, $n=81)$. Twenty new observations from six publications were included in the updated meta-analysis. The sample size for legume WCCs increased only 25\%, but the major areas sampled in the first meta-analysis are still represented: Canada, the Southeast, and North Central regions of the United States. The distribution of RR was significantly nonhomogeneous $(\mathrm{Q}=352.25, n=101, p$ $<0.001$; table 4 ), and between-studies variance was 0.016 . Differences between studies accounted for $70 \%$ of total variation in yield response for legume observations $\left(\mathrm{I}^{2}=70\right)$. The homogeneity analysis for legume WCCs revealed significant effects for tillage, region, and NFR in moderating the yield response $(p=0.01$ and $p<0.01$, respectively; table 5). Because region was a significant moderator of differences overall (table 3), it is analyzed separately in the next section.

As evidenced by the homogeneity analysis for NFR within legume WCCs, the RR decreased with increasing NFR (figure 4). For low $\mathrm{N}$ rates (0 to $99 \mathrm{~kg} \mathrm{ha}^{-1}$ [0 to 88.3 $\left.\left.\mathrm{lb} \mathrm{ac}^{-1}\right]\right)$, corn yields were significantly higher following a legume WCC than following NC. As $\mathrm{N}$ rates increased from 100 to 199 $\mathrm{kg} \mathrm{ha}^{-1}$ (89.2 to $177.5 \mathrm{lb} \mathrm{ac}^{-1}$ ), yield increases following a legume WCC were only 9\%. Yields for legume WCCs and NC were not significantly different when $\mathrm{N}$ fertilizer was $200 \mathrm{~kg} \mathrm{ha}^{-1}\left(178.4 \mathrm{lb} \mathrm{ac}^{-1}\right)$ or higher. These findings are similar to those reported by Miguez and Bollero (2005) and relate to lesser yield response at high NFR because of considerable $\mathrm{N}$ mineralization and $\mathrm{N}$ release following legume residue decomposition. Legumes symbiotically fix and supply significant amounts of $\mathrm{N}$ (Blanco-Canqui et al. 2015), providing rapid release of mineralized $\mathrm{N}$ when their residues, of good quality and $\mathrm{C} / \mathrm{N}$ ratios of 20 or less, decompose (Dabney et al. 2001). Miguez and Bollero (2006) analyzed corn response to hairy vetch (Vicia villosa), finding higher yields relative to $\mathrm{NC}$ at low and high $\mathrm{N}$ rates, suggesting that legume WCC benefits result from improved soil $\mathrm{N}$ availability but can also extend beyond $\mathrm{N}$ supply. For example, legumes have been shown to provide non-N-related benefits even at considerably high fertilizer rates, such as reduced soil evaporation and increasing soil moisture savings in warmer climates (Clark 
et al. 1997). Furthermore, legume WCC benefits seem to accrue when more than a single species is used. For example, early season $\mathrm{N}$ was positively correlated with yield increases up to $2.6 \mathrm{Mg} \mathrm{ha}^{-1}\left(1.16 \mathrm{tn} \mathrm{ac}^{-1}\right)$ for corn that followed more than one legume WCC (Smith et al. 2008), which could be explained through ecological mechanisms hypothesized for the over yielding capacity of non-N fixing species growing along with multiple legumes in unmanaged ecosystems.

The homogeneity analysis for legume showed also that the RR increased when tillage system changed from conventional to no-tillage (NT) (figure 5). Significant effects for tillage were not detected in the previous review (Miguez and Bollero 2005). Under CT, corn following legume WCCs exhibited yields 15\% higher than NC. Conversely, the yield increase was 30\% for NT corn following a legume WCC. WCC benefits are more rapidly realized in NT managed systems due to physical and chemical changes in the soil as a result of greater surface residue compared to CT (Blanco Canqui et al. 2015). Tillage breaks down soil aggregates and speeds up microbial decomposition of exposed residue, which in the case of legume WCCs can lead to rapid $\mathrm{N}$ mineralization and release when the soil is plowed (Balkcom et al. 2007). Subsequent lower corn yields under tillage systems may be the result of the asynchrony between $\mathrm{N}$ mineralization and the period of high $\mathrm{N}$ demand for the crop.

Region. The homogeneity test displayed significant differences in yield response to WCCs due to region (table 3 ). The North Central region of the United States experienced a seven-fold increase in sample size (i.e., 11 observations in the first meta-analysis) and 77 new observations in the update. The updated database included observations from Illinois (14), Iowa (22), Wisconsin (17), Minnesota (2), and Michigan (12) — states not represented before. The Southeast region and Canada comprised nine new observations each, representing a $10 \%$ increase in sample size. The Great Plains, excluded from the analysis in Miguez and Bollero (2005) due to a single observation available, increased its sample size to six observations and hence was included for analysis. Neither the Northeast nor the Northwest presented new observations. Due to an overall larger data set, CI for weighted mean RR moderated by region diminished considerably.

The homogeneity analysis showed significant differences across regions (figure

\section{Figure 4}

Mean response ratio (RR; yield of corn following winter cover crops/yield of corn following no cover [ycc/ync]) and $95 \%$ confidence interval (horizontal bars) for the three levels of nitrogen fertilizer rate (NFR) within legume.

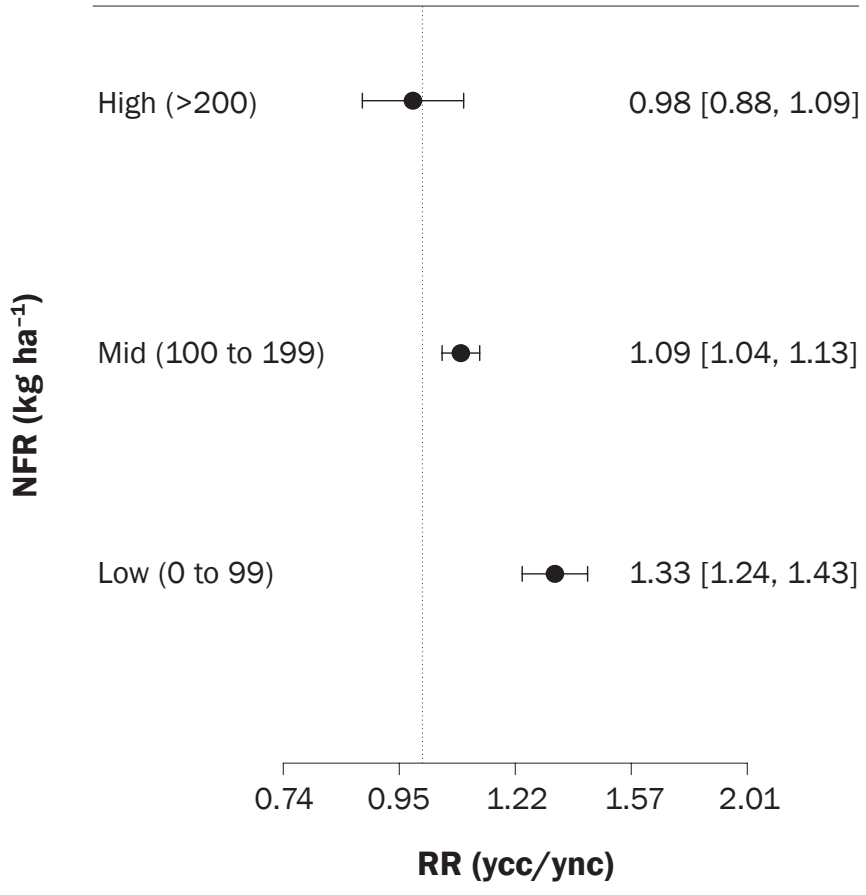

\section{Figure 5}

Mean response ratio (RR; yield of corn following winter cover crops/yield of corn following no cover [ycc/ync]) and $95 \%$ confidence interval (horizontal bars) for the two levels of tillage within legume, no-tillage (NT) and conventional tillage (CT).

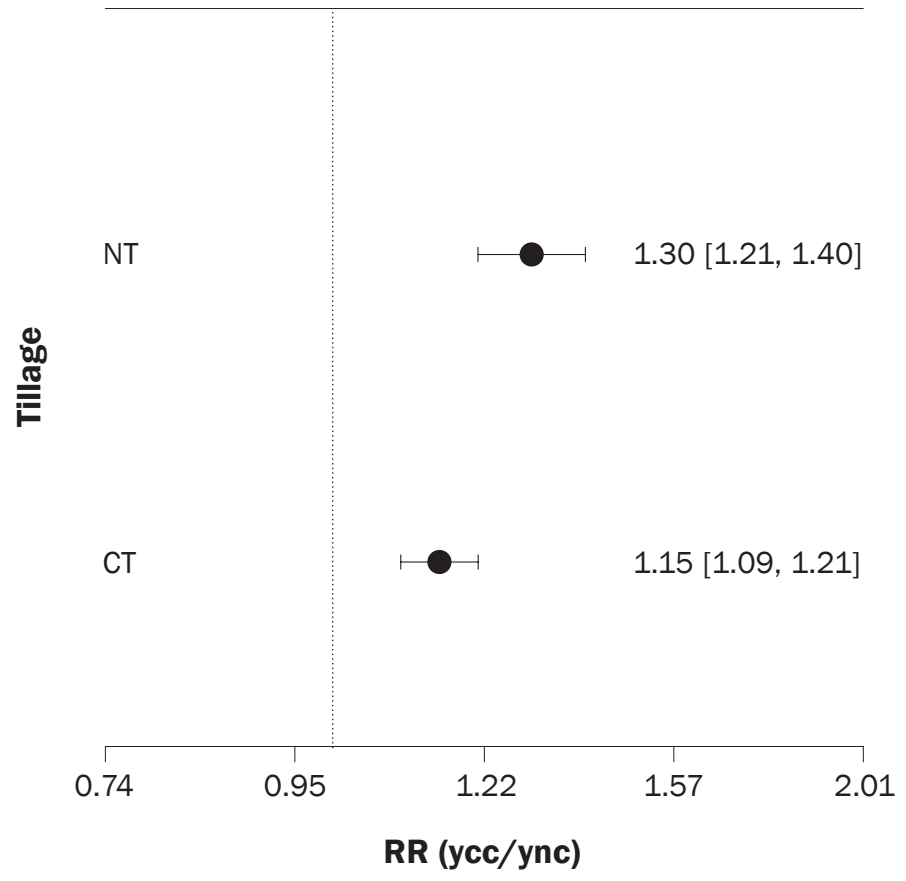


6). The CI for weighted mean RR encompassed 1 for the Great Plains, Canada, and North Central regions. Thus, yield response to WCCs in these regions were not significantly different from NC. The lack of differences between corn with WCCs and $\mathrm{NC}$ is a consequence of the limited yield benefits expected from short growth seasons and severe winters in northern regions. In view of these constraints, WCCs are likely grown for their benefits unrelated to yield. For instance, WCCs are grown to sequester out-of-season $\mathrm{NO}_{3}^{-}-\mathrm{N}$ and improve water quality, which is a high priority in Corn Belt states (Kladivko et al. 2014). In addition, challenging establishment limits adoption of other species (Singer 2008), and overseeding winter-hardy small cereals into corn is sometimes the most viable option (Snapp et al. 2005). Thus, it is not surprising that grass WCCs predominate in much of the North Central region, where yield benefits might be marginal, yet the environmental impact is considerable. On the other hand, Southeast and Northeast regions showed positive and significant effects of WCCs. Weighted mean $\mathrm{RR}$ for these regions were 1.12 and 1.14 , respectively, with 95\% CI not including 1. It follows that corn with WCCs yielded between $12 \%$ and $14 \%$ above NC.These findings are similar to those reported by Miguez and Bollero (2005). Southern warmer climates offer conditions for better establishment of heat tolerant species that grow rapidly, control weeds efficiently, and respond favorably to irrigation (Ngouajio and Mennan 2005; Snapp et al. 2005). WCCs alongside other conservation practices have been successfully implemented to restore eroded coarse textured soils in humid southern regions without losing productivity (Sainju et al.2002). Grasses and legumes have been successfully tested in Alabama, where winter rye showed neutral effects in subsequent corn biomass yields (Mourtzinis et al. 2015), whereas dense tropical legumes increased yield and $\mathrm{N}$ content of the subsequent grain corn (Balkcom and Reeves 2005).

Meta-Regression. The mixed models included NFR and WCC termination as explanatory variables, which explained a significant amount of variability in the RR. The main effect of WCC type was significant in the NFR and WCC termination models, which were run independently due to unequal number of observations and to avoid overparametrization if included

\section{Figure 6}

Mean response ratio (RR; yield of corn following winter cover crops/yield of corn following no cover [ycc/ync]) and $95 \%$ confidence interval (horizontal bars) for the six levels of region.

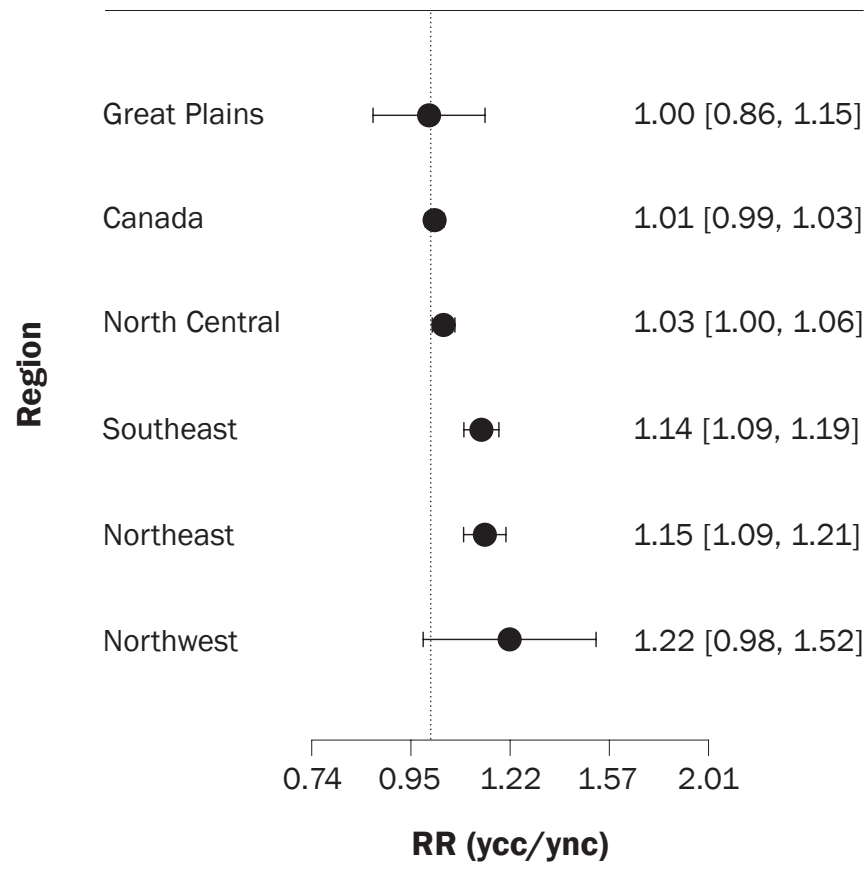

together in a full model. However, only the interaction NFR $\times$ WCC displayed significant effects on yield response. The regression coefficients for the NFR model were therefore analyzed further (table 6).

The intercepts for mixture and legume were statistically different from 1 (i.e., no WCCs effect), indicating that yields for unfertilized corn were $18 \%$ to $42 \%$ greater when the previous WCC was a mixture or a legume. The magnitude and direction of the slope was different for legume and mixture WCCs (figure 7). With increasing $\mathrm{N}$ rates, the $\mathrm{RR}$ for mixture seems to remain unchanged, whereas the legume $R R$ decreased. The yield gap between corn with WCCs and NC, which is more noticeable at lower $\mathrm{N}$ rates and narrows down with high NFR, has been substantiated by previous corn response models (Smith et al. 1987; Miguez and Bollero 2005; Miguez and Bollero 2006). Legume WCC contribution to higher yields at low NFR seems to be related to higher $\mathrm{N}$ mineralization, but some studies have found comparable or even greater yields than NC as NFR increases or more than one species is used, suggesting WCC benefits beyond N supply, such as soil moisture conservation, supply of other nutrients, or reduction of pest pressure (Ebelhar et al. 1984; Blanco-Canqui et al. 2015). For grass WCCs on the contrary, neither the intercept nor the slope were significant in this analysis (figure 7), indicating that corn following grass or NC responded similarly to N (Miguez and Bollero 2005; Pantoja et al. 2015). Grass WCCs do not increase soil $\mathrm{N}$ substantially. In fact, $\mathrm{N}$ is either retained in the WCC biomass or immobilized by microbes that decompose high $\mathrm{C} / \mathrm{N}$ ratio residues (Krueger et al. 2010). Even if $\mathrm{N}$ is recycled to the soil, the synchrony between high crop demand and $\mathrm{N}$ recycling from the residue could simply not occur, for which $\mathrm{N}$ application rates for corn under typical management conditions in the Midwest should be the same regardless of the inclusion of grass WCCs (Pantoja 2015).

The regression coefficients for the WCCs termination model were not significant (table 7). This result implies that corn yields were not significantly different between WCCs and NC whether the cover crop was earlyor late-terminated. Although the intercept did not differ statistically from 1 in all three WCC types, the RR for legume and mixture was higher than grass for WCCs terminated zero days before corn (i.e., late termination). Similarly, corn yields following legume and mixture were comparable to NC with a slight, yet not significant, increase at early termination (i.e., 14 days or more before corn). 


\section{Table 6}

Analysis of variance (ANOVA) and estimates for the regression parameters illustrating the relationship between the response ratio and two explanatory variables (winter cover crop species [WCC] and nitrogen fertilizer rate [NFR]).

\begin{tabular}{|c|c|c|c|c|c|c|}
\hline \multicolumn{3}{|l|}{ ANOVA } & & & & \\
\hline Source & $\mathbf{F}$ & $p$-value & & & & \\
\hline WCC & 51.63 & $<0.001$ & & & & \\
\hline NFR & 17.30 & $<0.001$ & & & & \\
\hline WCC $\times$ NFR & 32.13 & $<0.001$ & & & & \\
\hline \multicolumn{7}{|c|}{ Parameter estimates } \\
\hline wcCs & Intercept & $\begin{array}{l}\text { Lower } \\
\text { CL for } \\
\text { intercept }\end{array}$ & $\begin{array}{l}\text { Upper } \\
\text { CL for } \\
\text { intercept }\end{array}$ & Slope & $\begin{array}{l}\text { Lower } \\
\text { CL for } \\
\text { slope }\end{array}$ & $\begin{array}{l}\text { Upper } \\
\text { CL for } \\
\text { slope } \\
\end{array}$ \\
\hline Mixture & 1.18 & 1.07 & 1.30 & -0.00076 & -0.00206 & 0.00054 \\
\hline Grass & 0.92 & 0.84 & 1.00 & 0.00030 & -0.00020 & 0.00092 \\
\hline Legume & 1.43 & 1.35 & 1.50 & -0.00340 & -0.00280 & -0.00134 \\
\hline
\end{tabular}

Note: $\mathrm{CL}=95 \%$ confidence limits.

Sensitivity Analysis and Publication Bias. The cumulative meta-analysis by publication year displayed a decreasing but not always significant time trend in yield response to WCCs (figure 8). Thus, only studies from the mid-1980s to early 1990s reported mean RRs that did not encompass 1 . Mean RRs for this period were between 1.17 and 1.20, suggesting yields $17 \%$ to $20 \%$ higher for corn following WCCs. These studies tested WCC performance of different species, but were mostly conducted in the southeast United States (Frye et al. 1985; Varco et al. 1989; Utomo at al. 1990) where positive yields have resulted from soil improvement and $\mathrm{N}$ cycling of legume WCCs. On the other hand, before 1985 or after 1991, CMA revealed a decreasing yet not statistically significant trend of yield response to WCCs. Interestingly, for the time period considered for this meta-analysis update (2005 to 2015), RRs were not different from 1. Comparable yields for corn with and without WCCs in this period are the result of research with predominance of grass WCCs in the North Central United States, which were shown to pose neutral effects on subsequent corn. Noticeably, CMA demonstrates that the uncertainty around the mean response (95\% $\mathrm{CI})$ has been reduced since the first publications in the late 1960 to early 1970s, which changed considerably in early studies and stabilized as the whole set of studies was completed. CMA in other biological sciences have shown similar reductions in uncertainty around cumulative mean effect sizes when the time span of analysis was large and study distribution was uneven (Leimu and Koricheva 2004; Simmonds et al. 1999). From the sensitivity analysis, we found that as yield response to WCCs stabilizes and uncertainty around the RR decreases, a more adequate description of overall effect is expected. However, the exploration of corn yield progression affected by WCCs was not exhaustive, and future research should consider analyzing the sensitivity of results to factors other than publication year, such as journal impact factor or study time length.

Publication bias was not detected through funnel plots of RR against a measurement of study variability (i.e., inverse of standard error). Individual RRs were symmetrically distributed around the mean effect size (figure 9). As in the previous meta-analysis, no direct relationship emerged between $\mathrm{RR}$ and precision (i.e., lower study variance) (Anzures-Cabrera and Higgins 2010), for which reports of exclusively significant WCC effects in our data set were unlikely.

\section{Figure 7}

Relationship between the response ratio (RR; yield of corn following winter cover crops/yield of corn following no cover [ycc/ync]) and the continuous variable nitrogen fertilizer rate (NFR) for (a) grass, (b) legume, and (c) mixture winter cover crops.

(a)

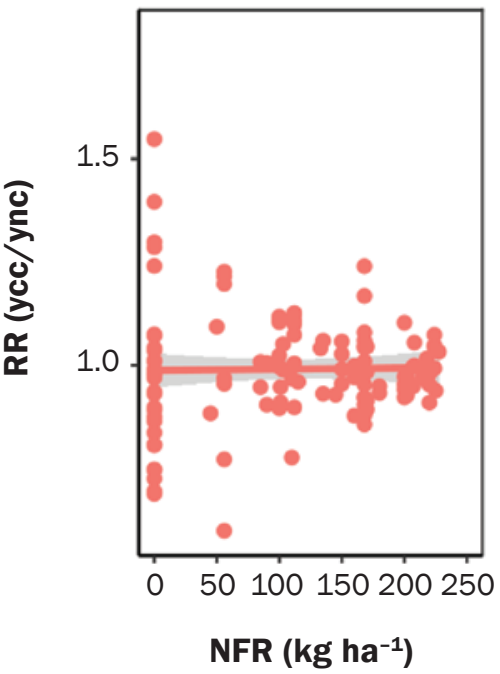

(b)

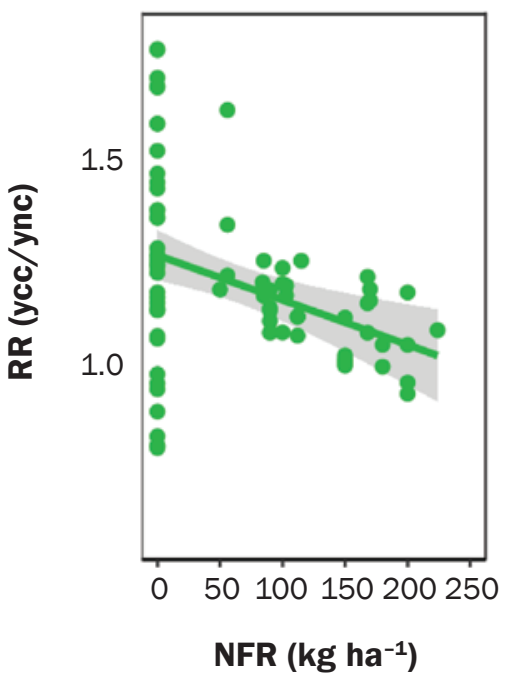

(c)

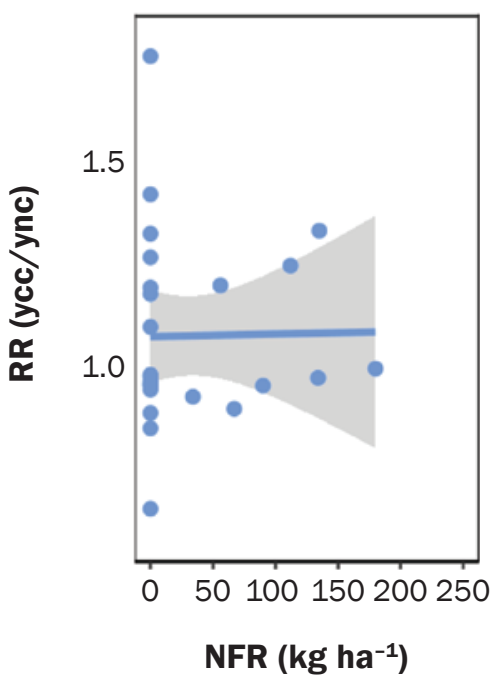




\section{Summary and Conclusions}

We updated the overall corn yield response to WCCs based on peer-reviewed publications from the last ten years (2005 to 2015). The authors confirmed and expanded the conclusions of the previous meta-analysis regarding WCC contribution to corn yields. Evidence from this update suggests an overall neutral to positive influence of WCCs on corn production in the United States and Canada. Much of the variability in WCC effects reported among publications arise from differences in management across regions. On average, grass WCCs neither increased nor decreased corn yields, although corn grown for grain yielded relatively higher than silage corn. In turn, mixture WCCs show an overall positive effect on corn yields, which is significantly higher at late termination of the cover crop. Legume WCCs contribute to higher corn yields when $\mathrm{N}$ fertilizer rates are low, or the tillage systems shifts from CT to NT. When analyzed in retrospective, however, WCCs contributed to higher corn yields mainly during the mid-1980s to early 1990s. Early research during this period emphasized testing of WCC species with potential to establish early and provide benefits under warmer conditions. WCC research of the last decades summarized for this review, however, has been directed towards practices that address challenging conditions for establishment in temperate areas, where soil benefits can be maximized but corn yields are not directly improved.

The evidence in this review shows the potential of WCCs to maintain or increase corn yields. However, incentives for WCC adoption should also consider factors beyond expectations for yield increases, such as improvements in nutrient cycling, water conservation, and erosion control. Because of future changing conditions to which farmers must adapt, results from this review should guide future evaluation of topics of limited exploration to date, such as field experiments involving more diverse WCC mixtures, or quantitative assessments of long-term cover crop impacts on soil and water conservation.

\section{Acknowledgements}

This research is part of a regional collaborative project supported by the USDA National Institute of Food and Agriculture (NIFA), Award No. 2011-68002-30190, Cropping Systems Coordinated Agricultural Project: Climate Change, Mitigation, and Adaptation in Cornbased Cropping Systems. The authors appreciate personnel
Table 7

Analysis of variance (ANOVA) and estimates for the regression parameters illustrating the relationship between the response ratio and two explanatory variables (winter cover crop species [WCC] and termination [T]).

\begin{tabular}{|c|c|c|c|c|c|c|}
\hline \multicolumn{3}{|l|}{ ANOVA } & & & & \\
\hline Source & $\mathbf{F}$ & $p$-value & & & & \\
\hline WCC & 36.86 & $<0.001$ & & & & \\
\hline $\mathrm{T}$ & 0.06 & 0.801 & & & & \\
\hline WCCs $\times T$ & 0.53 & 0.587 & & & & \\
\hline \multicolumn{7}{|c|}{ Parameter estimates } \\
\hline WcCs & Intercept & $\begin{array}{l}\text { Lower } \\
\text { CL for } \\
\text { intercept }\end{array}$ & $\begin{array}{l}\text { Upper } \\
\text { CL for } \\
\text { intercept }\end{array}$ & Slope & $\begin{array}{l}\text { Lower } \\
\text { CL for } \\
\text { slope }\end{array}$ & $\begin{array}{l}\text { Upper } \\
\text { CL for } \\
\text { slope }\end{array}$ \\
\hline Mixture & 1.19 & 1.06 & 1.33 & -0.00311 & -0.00150 & 0.00866 \\
\hline Grass & 0.96 & 0.89 & 1.05 & -0.00030 & -0.00610 & 0.00535 \\
\hline Legume & 1.27 & 1.19 & 1.36 & 0.00316 & -0.00386 & 0.01007 \\
\hline
\end{tabular}

Note: $\mathrm{CL}=95 \%$ confidence limits.

\section{Table 8}

Reference, location, and winter cover crop (WCC) species used for 28 studies included in the updated meta-analysis (2005 to 2015)*.

\begin{tabular}{lll}
\hline Reference & Locations & WCC speciest \\
\hline Andraski and Bundy 2005 & Hancock, Wisconsin & $\mathrm{G}$ \\
Balkcom and Reeves 2005 & Shorter, Alabama & $\mathrm{L}$ \\
Bich et al. 2014 & Andover, Trail City, and Aurora, South Dakota & $\mathrm{M}$ \\
Bundy and Andraski 2005 & Hancock, Wisconsin & $\mathrm{G}$ \\
Crandall et al. 2005 & Urbana, Illinois & $\mathrm{G}$ \\
Dietzel et al. 2016 & Boone, lowa & $\mathrm{G}$ \\
Duiker and Curran 2005 & Rock Springs, Pennsylvania & $\mathrm{G}$ \\
Fronning et al. 2008 & East Lansing, Michigan & $\mathrm{G}$ \\
Hashemi et al. 2013 & South Deerfield, Massachusetts & $\mathrm{G}$ \\
Kaspar and Bakker 2015 & Boone, lowa & $\mathrm{G}$ \\
Kaspar et al. 2012 & Boone, lowa & $\mathrm{G}$ \\
Kaspar et al. 2007 & Boone, lowa & $\mathrm{G}$ \\
Krueger et al. 2011 & Morris, Minnesota & $\mathrm{G}$ \\
Lawley et al. 2011 & Beltsville, Maryland & $\mathrm{G}$ \\
Miguez and Bollero 2006 & Urbana, Illinois & $\mathrm{G}, \mathrm{L}, \mathrm{M}$ \\
Moore et al. 2014 & Boone, lowa & $\mathrm{G}$ \\
Mourtzinis et al. 2015 & Alabama & $\mathrm{G}$ \\
Olson et al. 2010 & Dixon Springs, Illinois & $\mathrm{G}$ \\
Pantoja et al. 2015 & Boone, Crawford, Lewis, and Nashua, lowa & $\mathrm{G}$ \\
Parkin and Kaspar 2006 & Boone, lowa & $\mathrm{G}$ \\
Parr et al. 2011 & Plymouth and Salisbury, North Carolina & L \\
Reese et al. 2014 & Andover and Trail City, South Dakota & $\mathrm{M}$ \\
Singer and Kohler 2005 & Boone, lowa & $\mathrm{G}$ \\
Singer et al. 2008 & Boone, lowa & $\mathrm{G}$ \\
Smith et al. 2008 & Michigan & L, M \\
Thilakarathna et al. 2015 & Elora, Ontario (Canada) & $\mathrm{L}, \mathrm{G}$ \\
Welch et al. 2016 & Cerro Gordo, Malta, and Pana, Illinois & $\mathrm{M}$ \\
Wortman et al. 2012 & Mead, Nebraska & $\mathrm{M}$ \\
\hline
\end{tabular}

* For a full description of the studies in the first meta-analysis (1965 to 2004), see Appendix A in Miguez and Bollero (2005).

†Winter cover crop species: $L=$ legume, $G=$ grass, and $M=$ mixture. 


\section{Figure 8}

Cumulative response ratio (RR; yield of corn following winter cover crops/yield of corn following no cover [ycc/ync]) and $95 \%$ confidence interval (horizontal bars). A ratio represents the cumulative weighted mean computed for all the studies published in the same year.

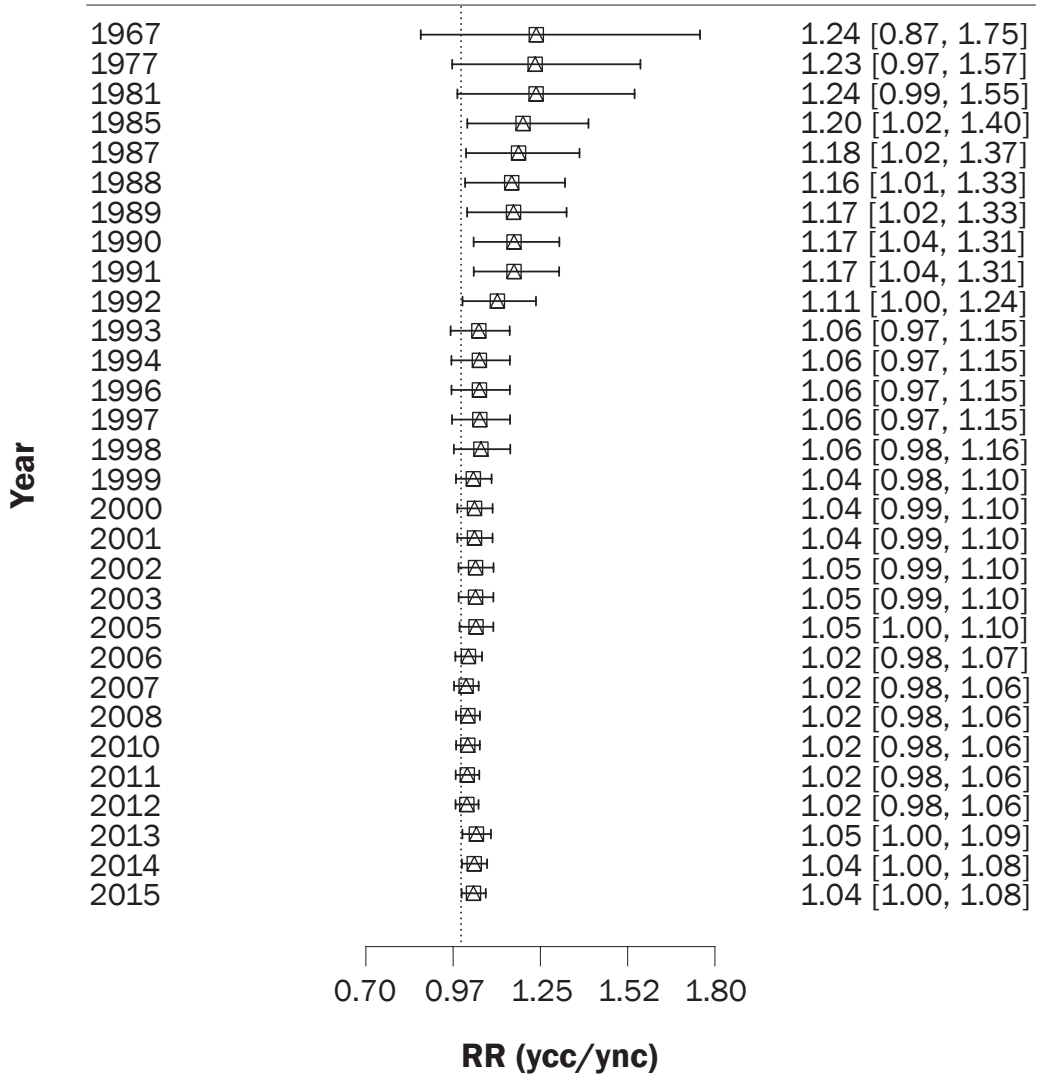

\section{Figure 9}

Inverse standard error associated with each observation included in the meta-analysis against effect size (log [yield of corn following winter cover crop/yield of corn following no cover]).

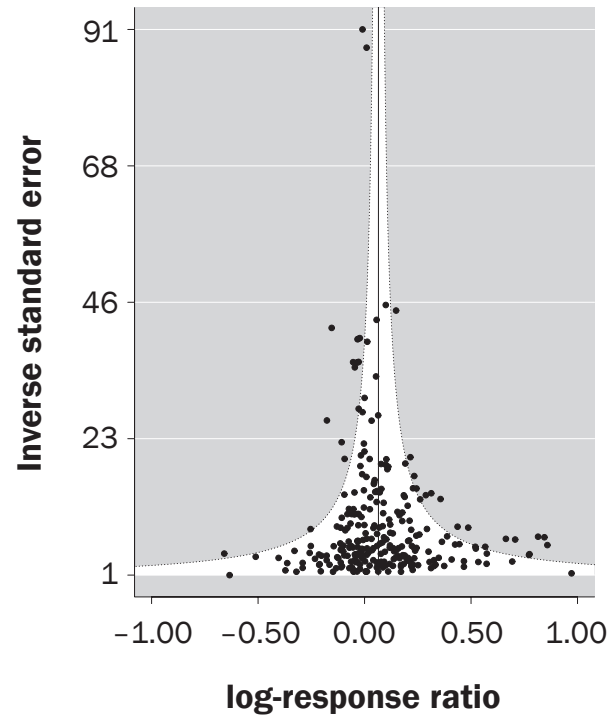

of the Miguez Agro-ecosystem Modeling Lab at Iowa State University (Ames, Iowa) for their inputs at different stages of this research. Appreciation is also extended to Yeganneh Gharabigloozare and Edel Aaron, undergraduate lab assistants at Iowa State University (Ames, Iowa), for their support in data preparation. We thank also Jeremy Singer (USDA scientist at the National Laboratory for Agriculture and the Environment [NLAE] in Ames, Iowa), and Cynthia Cambardella, Thomas Moorman, and Keith Kohler (USDA research scientists at the NLAE in Ames, Iowa) for providing prompt responses and additional information.

\section{References}

Andraski, T.W., and L.G. Bundy. 2005. Cover crop effects on corn yield response to nitrogen on an irrigated sandy soil. Agronomy Journal 97(4):1239-1244.

Anzures-Cabrera, J., and J.P. Higgins. 2010. Graphical displays for meta-analysis: An overview with suggestions for practice. Research Synthesis Methods 1(1):66-80.

Arnqvist, G., and D. Wooster. 1995. Meta-analysis: Synthesizing research findings in ecology and evolution. Trends in Ecology and Evolution 10(6):236-40.

Badgley, C., J. Moghtader, E. Quintero, E. Zakem, M.J. Chappell, K. Avilés-Vázquez, A. Samulon, and I. Perfecto. 2007. Organic agriculture and the global food supply. Renewable Agriculture and Food Systems 22(02):86.

Balkcom, K.S., and D.W. Reeves. 2005. Sunn-hemp utilized as a legume cover crop for corn production. Agronomy Journal 97(1):26-31.

Balkcom, K.S., H. Schomberg, D.W. Reeves, A.J. Clark, L. Baumbardt, C. Hal, J.A. Delgado, S.W. Duiker, T.C. Kaspar, and J. Mitchell. 2007. Managing cover crops in conservation tillage systems. In Managing Cover Crops Profitably, ed. A.J. Clark. College Park, MD: Sustainable Agriculture Research and Education.

Basche, A.D., F.E. Miguez, T.C. Kaspar, and M.J. Castellano. 2014. Do cover crops increase or decrease nitrous oxide emissions? A meta-analysis. Journal of Soil and Water Conservation 69(6):471-82, doi:10.2489/jswc.69.6.471.

Bates, D., M. Mächler, B.M. Bolker, and S.C. Walker. 2015. Fitting linear mixed-effects models using lme4. Journal of Statistical Software 67(1).

Bich, A.D., C.L. Reese, A.C. Kennedy, D.E. Clay, and S.A. Clay. 2014. Corn yield is not reduced by mid-season establishment of cover crops in northern Great Plains environments. Crop Management 13(1):1-8.

Blanco-Canqui, H., T.M. Shaver, J.L. Lindquist, C.A. Shapiro, R.W. Elmore, C.A. Francis, and G.W. Hergert. 2015. Cover crops and ecosystem services: Insights from studies in temperate soils. Agronomy Journal 107(6):2449-74.

Borenstein, M., L.V. Hedges, J.P.T. Higgins, and H.R. Rothstein. 2010. A basic introduction to fixed-effect and random-effects models for meta-analysis. Research Synthesis Methods 1(2):97-111.

Bundy, L.G., and T.W. Andraski. 2005. Recovery of fertilizer nitrogen in crop residues and cover crops on an irrigated 
sandy soil. Soil Science Society of America Journal 69(3):640.

Challinor, A.J., J. Watson, D.B. Lobell, S.M. Howden, D.R. Smith, and N. Chhetri. 2014. A meta-analysis of crop yield under climate change and adaptation. Nature Climate Change 27(March):1-5.

Clark, A.J., A.M. Decker, J.J. Meisinger, and M.S. McIntosh. 1997. Kill date of vetch, rye, and a vetch-rye mixture: II. Soil moisture and corn yield. Agronomy Journal 89(3):434-41.

Crandall, S.M., M.L. Ruffo, and G.A. Bollero. 2005. Cropping system and nitrogen dynamics under a cereal winter cover crop preceding corn. Plant and Soil 268 (1):209-19.

Dabney, S., J.A. Delgado, and D.W. Reeves. 2001. Using winter cover crops to improve soil and water quality. Communications in Soil Science and Plant Analysis 32(7-8):1221-1250.

Dietzel, R., M. Liebman, R. Ewing, M. Helmers, R. Horton, M. Jarchow, and S. Archontoulis. 2016. How efficiently do corn- and soybean-based cropping systems use water? A systems modeling analysis. Global Change Biology 22(2):666-81.

Duiker, S.W., and W.S. Curran. 2005. Rye cover crop management for corn production in the northern midAtlantic region. Agronomy Journal 97(5):1413-18.

Dunn, M., L.S. Prokopy, R.L. Myers, C.R. Watts, and K. Scanlon. 2016. Perceptions and use of cover crops among early adopters: Findings from a national survey. Journal of Soil and Water Conservation 71(1):29-40, doi:10.2489/jswc.71.1.29.

Ebelhar, S.A, W.W. Frye, and R.L. Blevins. 1984. Nitrogen from legume cover crops for no-tillage corn. Agronomy Journal 76:51-55.

Eckert, D.J. 2013. Rye cover crops for no-tillage corn and soybean production. Journal of Production Agriculture 210(127):207-10.

Fageria, N.K., V.C. Baligar, and B.A. Bailey. 2005. Role of cover crops in improving soil and row crop productivity. Communications in Soil Science and Plant Analysis 36(19-20):2733-2757.

Fronning, B.E., K.D. Thelen, and D. Hong Min. 2008. Use of manure, compost, and cover crops to supplant crop residue carbon in corn stover removed cropping systems. Agronomy Journal 100(6):1703-10.

Frye,W.W., R.L. Blevins, M.S. Smith, J.J. Corak, and J.J.Varco. 1988. Role of Annual Legume Cover Crops in Efficient Use of Water and Nitrogen. In Cropping Strategies for Efficient Use of Water and Nitrogen, ed. B.G. Ellis, and W.L. Hargrove. ASA Special Issue no. 51. 129-54. Madison, WI:The American Society of Agronomy, Crop Science Society of America, and Soil Science Society of America.

Frye, W.W., W.G. Smith, and R.J. Williams. 1985. Economics of winter cover crops as a source of nitrogen for no-till corn. Journal of Soil and Water Conservation $40(2): 246-249$.
Hartwig, N.L., and H.U. Ammon. 2002. Cover crops and living mulches. Weed Science 50(6):688-99.

Hashemi, M., A. Farsad, A. Sadeghpour, S.A. Weis, and S.J. Herbert. 2013. Cover-crop seeding-date influence on fall nitrogen recovery. Journal of Plant Nutrition and Soil Science 176(1):69-75.

Higgins, J.P., and S.G. Thompson. 2002. Quantifying heterogeneity in a meta-analysis. Statistics in Medicine 21(11):1539-1558.

Huedo-Medina, T.B., J. Sanchez-Meca, F. Marin-Martinez, and J. Botella. 2006. Assessing heterogeneity in metaanalysis: Q statistic or $\mathrm{I}^{2}$ index? Psychological Methods 11(2):193-206.

ILF (Iowa Learning Farms). 2015. Building a Culture of Conservation. The Economic Value of Cover Crops. https://www.iowalearningfarms.org/files/page/files/ Cover_Crops_economics_4pp_0.pdf.

INRS (Iowa Nutrient Reduction Strategy). 2016. A Science and Technology-based Framework to Assess and Reduce Nutrients to Iowa Waters and the Gulf of Mexico. http://www.nutrientstrategy.iastate.edu/sites/default/ files/documents/INRSfull-161001.pdf.

IPCC (Intergovernmental Panel on Climate Change) 2007. Climate Change 2007: Impacts, Adaptation and Vulnerability. Contribution of Working Group II to the Fourth Assessment Report of the Intergovernmental Panel on Climate Change. Cambridge, UK, and New York, NY, USA: Intergovernmental Panel on Climate Change.

Kaspar,T.C., and M.G. Bakker. 2015. Biomass production of 12 winter cereal cover crop cultivars and their effect on subsequent no-till corn yield. Journal of Soil and Water Conservation 70(6):353-64, doi:10.2489/jswc.70.6.353.

Kaspar, T.C., D.C. Erbach, and R.M. Cruse. 1990. Corn response to seed-row residue removal. Soil Science Society of America Journal 54:1112-1117.

Kaspar, T.C., D.B. Jaynes, T.B. Parkin, and T.B. Moorman. 2007. Rye cover crop and gamagrass strip effects on NO concentration and load in tile drainage. Journal of Environment Quality 36(5):1503.

Kaspar, T.C., D.B. Jaynes, T.B. Parkin, T.B. Moorman, and J.W. Singer. 2012. Effectiveness of oat and rye cover crops in reducing nitrate losses in drainage water. Agricultural Water Management 110(3):25-33.

Kaspar, T.C., J.K. Radke, and J.M. Laflen. 2001. Small grain cover crops and wheel traffic effects on infiltration, runoff, and erosion. Journal of Soil and Water Conservation 56(2):160-64.

Khoshravesh, M., M.A.G. Sefidkouhi, and M. Valipour. 2015. Estimation of reference evapotranspiration using multivariate fractional polynomial, bayesian regression, and robust regression models in three arid environments. Applied Water Science (2015):1-12, doi:10.1007/ s13201-015-0368-x.

Kiær, L., I. Skovgaards, and H. Østergard. 2009. Grain yield increase in cereal variety mixtures: A meta-analysis of field trials. Field Crops Research 114(3):361-73.
Kladivko, E., T.C. Kaspar, D.B. Jaynes, R.W. Malone, J. Singer, X.K. Morin, and T. Searchinger. 2014. Cover crops in the upper midwestern United States: Simulated effect on nitrate leaching with artificial drainage. Journal of Soil and Water Conservation 69(4):292-305, doi:10.2489/ jswc.69.4.292.

Krueger, E., T. Ochsner, M. Kantar, C. Sheaffer, and P. Porter. 2010. Growth stage at harvest of a winter rye cover crop influences soil moisture and nitrogen. Crop Management 9(1):00.

Krueger, E.S., T.E. Ochsner, P.M. Porter, and J.M. Baker. 2011. Winter rye cover crop management influences on soil water, soil nitrate, and corn development. Agronomy Journal 103(2):316-23

Kuo, S., and E.J. Jellum. 2000. Long-term winter cover cropping effects on corn (Zea Mays L.) production and soil nitrogen availability. Biology and Fertility of Soils 31(6):470-77

Kuo, S., and E.J. Jellum. 2002. Influence of winter cover crop and residue management on soil nitrogen availability and corn. Agronomy Journal 94(3):501-508

Kuo, S., and U.M. Sainju. 1998. Nitrogen mineralization and availability of mixed leguminous and non-leguminous cover crop residues in soil. Biology and Fertility of Soils 26(4):346-53

Lawley,Y.E., R.R.Weil, and J.R.Teasdale. 2011. Forage radish cover crop suppresses winter annual weeds in fall and before corn planting. Agronomy Journal 103(1):137-44.

Leimu, R., and J. Koricheva. 2004. Cumulative metaanalysis: A new tool for detection of temporal trends and publication bias in ecology. Proceedings. Biological Sciences. The Royal Society 271(1551):1961-1966.

Miguez, F.E., and G. Bollero. 2005. Review of corn yield response under winter cover cropping systems using meta-analytic methods. Crop Science 45(6):2318-2329.

Miguez, F.E., and G. Bollero. 2006. Winter cover crops in Illinois: Evaluation of ecophysiological characteristics of corn. Crop Science 46(4):1536-1545.

Moher, D., A. Tsertsvadze, A. Tricco, M. Eccles, J. Grimshaw, M. Sampson, and N. Barrowman. 2008. When and How to Update Systematic Reviews. Cochrane Database of Systematic Reviews (1):MR000023, doi:10.1002/14651858.MR000023.pub3

Moore, E.B., M.H. Wiedenhoeft, T.C. Kaspar, and C.A Cambardella. 2014. Rye cover crop effects on soil quality in no-till corn silage-soybean cropping systems. Soil Science Society of America Journal 78(3):968.

Mourtzinis, S., F. Arriaga, K.S. Balkcom, and A.J. Price. 2015 Vertical distribution of corn biomass as influenced by cover crop and stover harvest. Agronomy Journal 107(1):232

Munawar, A., R.L. Blevins, W.W. Frye, and M.R. Saul. 1990. Tillage and cover crop management for soil water conservation. Agronomy Journal 82:773-77.

Ngouajio, M., and H. Mennan. 2005. Weed populations and pickling cucumber (Cucumis Sativus) yield under 
summer and winter cover crop systems. Crop Protection 24(6):521-526.

O'Connor, D., S. Green, and J.P.T. Higgins. 2008. Cochrane Handbook for Systematic Reviews of Interventions, ed. J.P.T. Higgins and S. Green. Cochrane Book Series. West Sussex, UK: Wiley-Blackwell.

Olson, K.R., S.A. Ebelhar, and J.M. Lang. 2010. Cover crop effects on crop yields and soil organic carbon content. Soil Science 175(2):89-98.

Olson, R.A., W.R. Raun, Y.S. Chun, and J. Skopp. 1986. Nitrogen management and interseeding effects on irrigated corn and sorghum and on soil strength. Agronomy Journal 78(5):856.

Pai, M., M. Mcculloch, J.D. Gorman, N. Pai, W. Enanoria, G. Kennedy, P. Tharyan, J.M. Colford Jr., and J.M. Colford. 2004. Systematic reviews and meta-analyses: An illustrated, step-by-step guide. The Natural Medical Journal of India 17(2):86-95

Pantoja, J.L., K.P. Woli, J.E. Sawyer, and D.W. Barker. 2015. Corn nitrogen fertilization requirement and cornsoybean productivity with a rye cover crop. Soil Science Society of America Journal 79:1482-1495.

Parkin, T.B., and T.C. Kaspar. 2006. Nitrous oxide emissions from corn-soybean systems in the Midwest. Journal of Environment Quality 35(4):1496.

Parr, M., J.M. Grossman, S.C. Reberg-Horton, C. Brinton, and C. Crozier. 2011. Nitrogen delivery from legume cover crops in no-till organic corn production. Agronomy Journal 103(6):1578-90.

Ponisio, L.C., L.K. M'Gonigle, K.C. Mace, J. Palomino, P. De Valpine, and C. Kremen. 2015. Diversification practices reduce organic to conventional yield gap. Proceedings of the Royal Society B: Biological Sciences 282(20141396):1-7.

Reberg-Horton, S.C., J.D. Burton, G.Ma, D.A. Danehower, D.W. Monks, J.P. Murphy, N.N. Ranells, J.D. Williamson, and N.G. Creamer. 2005. Changes over time in the allelochemical content of ten cultivars of rye (Secale Cereale L.). Journal of Chemical Ecology 31(1):179-93.

Reese, C.L., D.E. Clay, S.A. Clay, A.D. Bich, A.C. Kennedy, S.A. Hansen, and J. Moriles. 2014. Winter cover crops impact on corn production in semiarid regions. Agronomy Journal 106(4):1479.

Reeves, D.W. 1994. Cover Crops and Rotations. In Advances in Soil Science: Crops Residue Management, ed. L. Hatfield and B.A. Steward, 125-172. Boca Raton, FL: CRC Press.

Ruffo, M.L., and G.A. Bollero. 2003. Residue decomposition and prediction of carbon and nitrogen release rates based on biochemical fractions using principal component regression. Agronomy Journal 95(4):1034-1040.

Sainju, U.M., and B.P. Singh. 2001. Tillage, cover crop, and kill-planting date effects on corn yield and soil nitrogen. Agronomy Journal 93(4):878-86.

Sainju, U.M., B.P. Singh, and W.F. Whitehead. 2002. Long-term effects of tillage, cover crops, and nitrogen fertilization on organic carbon and nitrogen concentrations in sandy loam soils in Georgia, USA. Soil and Tillage Research 63(3-4):167-79.

Seufert, V., N. Ramankutty, and J.A. Foley. 2012. Comparing the yields of organic and conventional agriculture. Nature 485:229-232.

Sileshi, G., F.K. Akinnifesi, O.C. Ajayi, and F. Place. 2008. Meta-analysis of maize yield response to woody and herbaceous legumes in sub-Saharan Africa. Plant and Soil 307(1-2):1-19.

Simmonds, L.W., J.L. Tomkins, J.S. Kotiaho, and A.J. Sutton. 1999. Fluctuacting Paradigm. Proceedings B of the Royal Society (266):593-595.

Singer, J.W. 2008. Corn Belt assessment of cover crop management and preferences. Agronomy Journal 100(6):1670-1672.

Singer, J.W., C.A. Cambardella, and T.B. Moorman. 2008. Enhancing nutrient cycling by coupling cover crops with manure injection. Agronomy Journal 100(6):1735-39.

Singer, J.W., and K.A. Kohler. 2005. Rye cover crop management affects grain yield in a soybean-corn rotation. Crop Management 4(1):1-8.

Singer, J.W., S.M. Nusser, and C.J. Alf. 2007. Are cover crops being used in the US Corn Belt? Journal of Soil and Water Conservation 62(5):353-358.

Smith, M.S., W.W. Frye, and J.J.Varco. 1987. Legume Winter Cover Crops. In Advances in Soil Science, ed. B.A. Steward, 95-139. New York, NY: Springer-Verlag.

Smith, R.G., K.L. Gross, and G.P. Robertson. 2008. Effects of crop diversity on agroecosystem function: Crop yield response. Ecosystems 11(3):355-66.

Snapp, S.S., S.M. Swinton, R. Labarta, D. Mutch, J.R. Black, R. Leep, and J. Nyiraneza. 2005. Cropping system niches. Agronomy Journal 97:322-332.

St-Pierre, N.R. 2001. Invited review: Integrating quantitative findings from multiple studies using mixed model methodology. Journal of Dairy Science (84):741-755.

Teasdale, J.R., and C.L. Mohler. 2000. The quantitative relationship between weed emergence and the physical properties of mulches. Weed Science 48(3):385-392.

Thilakarathna, M.S., S. Serran, J. Lauzon, K. Janovicek, and B. Deen. 2015. Management of manure nitrogen using cover crops. Agronomy Journal 107(4):1595.

Tillman, G., H. Schomberg, S. Phatak, B. Mullinix, S. Lachnicht, P. Timper, and D. Olson. 2004. Influence of cover crops on insect pests and predators in conservation tillage cotton. Journal of Economic Entomology 97(4):1217-32.

Tonitto, C., M.B. David, and L.E. Drinkwater. 2006 Replacing bare fallows with cover crops in fertilizerintensive cropping systems: A meta-analysis of crop yield and $\mathrm{N}$ dynamics. Agriculture, Ecosystems and Environment 112(1):58-72.

Truman, C.C., D.W. Reeves, J.N. Shaw, A.C. Motta, C.H Burmester, R.L. Raper, and E.B. Schwab. 2003. Tillage impacts on soil property, runoff, and soil loss variations from a Rhodic Paleudult under simulated rainfall Journal of Soil and Water Conservation 58(5):258-267.
Unger, P.W., and M.F. Vigil. 1998. Cover crop effects on soil water relationships. Journal of Soil and Water Conservation 53(3):200-207.

Utomo, M., W.W. Frye, and R.L. Blevins. 1990. Sustaining soil nitrogen for corn using hairy vetch cover crop. Agronomy Journal 82(5):979.

Valkama, E., R. Lemola, H. Känkänen, and E. Turtola. 2015. Meta-analysis of the effects of undersown catch crops on nitrogen leaching loss and grain yields in the Nordic countries. Agriculture, Ecosystems and Environment (203):93-101.

Van den Putte, A., G. Govers, J. Diels, K. Gillijns, and M. Demuzere. 2010. Assessing the effect of soil tillage on crop growth: A meta-regression analysis on European crop yields under conservation agriculture. European Journal of Agronomy 33(2010):231-241.

Varco, J.J., W.W. Frye, M.S. Smith, and C.T. MacKown. 1989. Tillage effects on nitrogen recovery by corn from a nitrogen-15 labeled legume cover crop. Soil Science Society of America Journal 53(3):822.

Viechtbauer, W. 2010. Conducting meta-analyses in R with the metafor package. Journal of Statistical Software 36(3):1-48.

Viechtbauer, W. 2015. Metafor meta-analysis package for R, Version 1.9-8. https://cran.r-project.org/web/ packages/metafor/.

Villamil, M.B., G.A. Bollero, R.G. Darmody, F.W. Simmons, and D.G. Bullock. 2006. No-till corn/soybean systems including winter cover crops. Soil Science Society of America Journal 70(6):1936.

Wagger, M.G., and D.B. Mengel. 1993. The Role of Nonleguminous Cover Crops in the Efficient Use of Water and Nitrogen. In Cropping Strategies for Efficient Use of Water and Nitrogen, ed.W.L. Hargrove, 115-27. Madison, WI: American Society of Agronomy, Crop Science Society of America, and Soil Science Society of America.

Welch, R.Y., G.D. Behnke, A.S. Davis, J. Masiunas, and M.B.Villamil. 2016. Using cover crops in headlands of organic grain farms: Effects on soil properties, weeds and crop yields. Agriculture, Ecosystems and Environment 216(2016):322-32.

Wortman, S.E., C.A. Francis, M.A. Bernards, E.E. Blankenship, and J.L. Lindquist. 2013. Mechanical termination of diverse cover crop mixtures for improved weed suppression in organic cropping systems. Weed Science 61(1):162-70.

Wortman, S.E., C.A. Francis, M.L. Bernards, R.A. Drijber, and J.L. Lindquist. 2012. Optimizing cover crop benefits with diverse mixtures and an alternative termination method. Agronomy Journal 104(5):1425-35.

Wösten, J.H.M., A. Lilly, A. Nemes, and C. Le Bas. 1999. Development and use of a database of hydraulic properties of European soils. Geoderma 90(3-4):169-85. 